\title{
LA REDUCCIÓN AL EGO PURO EN LA FENOMENOLOGÍA DE HUSSERL Y EL ADVAITA
}

\author{
JAVIER PÉREZ GUERRERO \\ Universidad Internacional de la Rioja
}

\begin{abstract}
RESUMEN: Este artículo trata de mostrar el espíritu más agustiniano y humanista de la fenomenología de Husserl, que ahonda en la subjetividad humana buscando un sentido no mundano a su existencia. Con el fin de destacar este aspecto de la filosofía de Husserl se establece una comparación entre la reducción fenomenológica transcendental y el método conocido como "vichara", enseñado por los maestros de la escuela advaita (o de la no-dualidad) de la India.
\end{abstract}

PALABRAS CLAVE: Advaita; ego; fenomenología; Husserl; reducción.

\section{The reduction to the pure ego in Husserl's Phenomenology and Advaita}

ABSTRACT: This article intends to show the most agustinian and humanistic spirit of Husserl's phenomenology, which goes deeply into human subjectivity finding a non-worldly sense to its existence. In order to underline this aspect of Husserl's philosophy it sets up a comparison between the phenomenological transcendental reduction and the method known as «vichara», taught by the masters of the advaita (or non-duality) school in India.

KEY WORDS: Advaita; ego; Husser; phenomenology; reduction.

\section{INTRODUCCIÓN}

La fenomenología de Husserl exige un cambio de la actitud humana natural. Si ese cambio no se produce, la fenomenología es malinterpretada: los prejuicios naturalistas la desvirtúan convirtiéndola en anécdota mentalista, en ejercicio introspectivo $^{1}$. Ese cambio de actitud se efectúa con la libre epojé, que es la clave de la reducción fenomenológica transcendental ${ }^{2}$. La creencia habitual en la existencia

1 Contra este malentendido se sigue reaccionando en la actualidad como ha hecho Jesús Adrián Escudero. Vid. EscudERo, J. A., «La actualidad de la fenomenología husserliana: superación de viejos tópicos y apertura de nuevos campos de exploración» en: Eidos, 18 (2012), 17 y ss.

2 La reducción fenomenológica es tematizada por primera vez en La Idea de la fenomenología (1907), pero su carácter transcendental es tratado fundamentalmente en Ideas I (1913), Las Conferencias de Londres (1922), las Conferencias de la Sorbona recogidas en las Meditaciones Cartesianas (1931) y La Crisis de las ciencias europeas y la fenomenología transcendental (1936). Para las citas textuales nos serviremos de las siguientes traducciones: $\mathrm{La}$ idea de la fenomenología, Herder, Barcelona, 201; Ideas relativas a una fenomenología pura y una filosofía fenomenológica, Fondo de Cultura Económica, México D. F., 1973; Las Conferencias de Londres. Método y filosofía fenomenológicos, Sígueme, Salamanca, 2012; Meditaciones Cartesianas, Tecnos, Madrid, 2009 y La Crisis de las Ciencia Europeas y la fenomenología transcendental, Crítica, Barcelona, 1991. Señalaremos la página de estas ediciones así como el volumen y la página correspondiente de la Husserliana. En las paráfrasis señalaremos el volumen y la página de esta misma colección de obras de Husserl. 
del mundo, que es la tesis que caracteriza a la actitud natural, y es además la base de todas las ciencias, puede que sea ingenua, pero desde luego no es inocua, puesto que oculta a la subjetividad en tanto que prescriptiva respecto a cualquier posible experiencia de ese mundo ${ }^{3}$. De esta manera, es imprescindible una cierta alteración del yo para acceder a esa subjetividad no mundana. La mirada mundana supone un cierto olvido de sí, y esa alteración del yo, un redescubrimiento de sí mismo.

Como veremos, la epojé husserliana no es una reflexión episódica porque no añade una nueva vivencia a otra anterior sino que, por el contrario, reduce toda vivencia a sí misma. Se trata de una reflexión transcendental, de una experiencia egológica (egologishe Erfahrung) que consiste en dar un paso atrás respecto a la posición de la actitud natural ${ }^{4}$, que se encuentra de entrada con el mundo como algo que está a la mano, ya constituido con sus características propias, con sus posibilidades de exploración y de uso. Con la reducción se llega «a partir de todo ser ya constituido, a la subjetividad absoluta que en última instancia lo constituye ${ }^{5}$. La reducción trascendental y la epojé que la acompaña suponen un estar por encima de la dación previa del mundo, de modo que "con y en esta liberación está dado el descubrimiento de la correlación universal (...) entre el mismo mundo y la conciencia del mundo ${ }^{6}$. En la experiencia egológica yo no estoy en el mundo, sino que el mundo es mundo de la vida (Lebenswelt) del yo que se revela como subjetividad absoluta, como la conciencia detrás del horizonte.

La nueva actitud no mundana es caracterizada como la del espectador desinteresado ${ }^{7}$ que contempla sus vivencias sin dejarse arrastrar por su dirección temática $^{8}$, sin tomar posición ante las mismas. La vivencia, en tanto que factum, es un fenómeno puro en el sentido de que se muestra a sí mismo, de que se me presenta en persona como una autodonación (Selbstgegebenheit). Esto es lo propio de la inmanencia de la conciencia: su efectiva autodalidad ${ }^{9}$. La autodonación no se justifica

3 Según Fink, la nueva actitud pregunta por ese detrás (hinter) del carácter mundano (Weltcharackter) que oculta la experiencia transcendental co-constituyente del mundo. Cfr. FINK, E., VI Cartesianische Meditation. Tel 1. Die Idee einer Transzendentalen Methodenlehre, Kluivert Academic Publishers, Dordrecht, 1988, 11.

4 En la fenomenología, la epojé no tiene el sentido escéptico de una mera abstención del juicio sino que es reductiva en dos sentidos: en tanto que un desprenderse de algo y en tanto que un volver a lo originario. Cfr. CARLSON, S., «Reducción monadológica y reducción fenomenológica: el problema de la reducción en Husserl y Richir» en: Eikasa. Revistadefilosofia. org, $(57,2002), \S 2$, párr. 2 y ss.

5 Landgrebe, L., El camino de la fenomenología, Editorial Sudamericana, Buenos Aires, $1968,41$.

6 Husserl, E., La Crisis cit., 159 (Die Krisis der europäischen wissenschaften und die transzendentale phänomenologie. Eine einleitung in die phänomenologische philosophie, Martinus Nijhoff, La Haya, 1976, 154) (en adelante Hua VI).

7 Cfr. Husserl, E., Cartesianische Meditationen und Pariser Vorträge, Martinus Nijhoff, La Haya, 1973, 73 (en adelante Hua I).

8 «La reflexión fenomenológica-trascendental considera el acto sin participar en él; no sigue su dirección temática: lo convierte en tema». SzILASI, W., Introducción a la fenomenología de Husserl, Amorrortu Editores, Buenos Aires, 2003, 89.

9 Cfr., Hua I. 54. 
por la inmanencia considerada como ingrediente que poseen ciertas cosas que ocurren en mi interior ( «lo inmanente, dirá el principiante, está dentro de mí; lo trascendente, fuera de mí» $\left.{ }^{10}\right)$, más bien de ella, de la autodonación que se constituye en la evidencia, obtenemos un nuevo sentido de inmanencia como anulación de todo lo mentado más allá de sí mismo. A lo transcendente en este sentido debemos atribuirle el índice de la exclusión, de la nulidad gnoseológica ${ }^{11}$.

La filosofía debe ignorar toda dación previa y constituirse en ciencia primera y universal que se justifique a sí misma y, con ello, sirva de fundamento a cualquier otro saber, pero, tras esta preocupación científica que siempre animó el trabajo intelectual de Husserl, existen motivos profundamente humanistas en su descubrimiento de la subjetividad transcendental. Con este descubrimiento se recupera un humanismo no naturalista, no antropológico ${ }^{12}$, como nueva meditación en torno al imperativo délfico «conócete a ti mismo», que en esa altura histórica de la cultura europea cobra un significado especial: la ciencia positiva se ha perdido en el mundo y, con ella, se ha perdido el hombre. Es preciso, mediante la epojé, perder el mundo para, posteriormente, recuperarlo como meditación universal sobre sí mismo: "Nolis foras ire, dice San Agustín, in te redi, in interiore homine habitat veritas ${ }^{13}$.

En la medida en que la fenomenología descubre esta experiencia transcendental de sí mismo, el filósofo se transforma en funcionario de la humanidad al emprender la mayor transformación (comparable a una conversión religiosa) a la que puede aspirar dicha humanidad ${ }^{14}$. Esta transformación consiste en ahondar en la subjetividad hasta reconocerse conciencia transcendental.

La actitud fenomenológica de Husserl consiste en abandonar el ser de la superficie para sumergirse en ese interior viviente del mundo que es la conciencia transcendental. No obstante, existe un peculiar antagonismo entre introducirse en esa dimensión de espiritualidad viviente ${ }^{15}$ y los intereses de la vida mundana.

El objetivo de este artículo es exponer la reducción fenomenológica al puro ego de Husserl mostrando sus limitaciones, desde el punto de vista de ese espíritu agustiniano que la anima, a través de la comparación entre su reducción y el método conocido como «vichara», enseñado por los maestros de la escuela advaita (o de la no-dualidad) de la India, que se inscribe históricamente en la tradición del vedanta. Para mantener ese espíritu agustiniano de ahondamiento en la subjetividad es preciso no detenerse en la actitud del espectador desinteresado. Los maestros advaitines también enseñan que es crucial abandonar la actitud ingenuamente interesada y alcanzar la actitud del puro testigo (que es necesariamente previa, porque, como señala Husserl, aporta los sentidos originarios de los que derivan todos los demás), pero insisten en que ésta debe ser también abandonada.

10 Husserl, E., La Idea de fenomenología cit., 62 (Die idee der Phänomenologie. Fünf Vorlesungen, Martinus Nijhoff, La Haya, 1973, 39) (en adelante Hua II).

11 Cfr. Hua II, 39.

12 Landgrebe, L., o. c. 275-6.

13 Husserl, E., Meditaciones cit., 204 (Hua I, 183).

14 Cfr. Hua VI, 140; 159.

15 Cfr. Hua VI, 121. 
El vedanta es uno de los seis darsanas (visiones) del hinduismo, es decir, de las tradiciones sapienciales en cuya raíz se encuentran las escrituras (shruti) del hinduismo. En el caso del vedanta, su fuente son en concreto los Upanishads, la colección de textos que conforman la parte última o final de los Vedas, aunque otros textos capitales del hinduismo, como el Bhagavad Gita, también son profusamente meditados y comentados en esta tradición. El vedanta es, siguiendo el camino abierto por los Upanishads y el Bhagavad Gita, una interiorización del sacrificio brahmánico: el sacrificio, la ofrenda, se da en el interior del propio hombre, es el propio hombre, de modo que descubrir esta verdad oculta es la ratificación del sacrificio (la verdad es, por lo tanto, sacrificial) y equivale a un retorno, pues es la respuesta humana a una primera ofrenda o sacrificio realizada por la divinidad. La escuela advaita se constituye probablemente tras recibir esta tradición el influjo de las enseñanzas budistas de Nagarjuna (siglos II-III d. C) y de Vasubandhu y su hermano, Asanga (siglo IV d. C) ${ }^{16}$, y no concede ningún carácter real a la multiplicidad considerada en sí misma sino sólo en el Sí mismo (Atman) que es el Ser o Uno sin segundo. Lo real no lo hay porque todo cuanto hay es irreal y considerarlo como subsistente es cubrirlo con el velo creador de ilusión de la ignorancia (maya). En el epígrafe cuarto volveremos a esta escuela al exponer vichara.

Pero ahora es conveniente precisar más el alcance y el sentido de esta comparación. El objeto del artículo no es realizar una comparación sin más entre dos métodos, alejados histórica y geográficamente, buscando afinidades y discrepancias. La finalidad de esta comparación es mostrar hasta dónde llega la reducción husserliana en ese ahondamiento en la subjetividad del que hablamos para, a partir de ahí, mostrar el modo según el cual una propuesta como la de vichara, que en buena parte es paralela a la reducción de Husserl, va más allá. Husserl, aunque su epojé sea libre, se atiene al criterio de evidencia y no puede abandonar completamente lo dado (ya hemos visto que la evidencia es la autodalidad). La reducción se detiene en un yo puro, sin atributos, que no está dado, pero que, sin embargo, es lo único absolutamente evidente y apodíctico ${ }^{17}$ porque cualquier dato que podamos considerar o tener en cuenta lo demuestra. Es indubitable porque la misma duda, en tanto que se da, lo demuestra. Es innegable porque la misma negación, en tanto que se da, lo demuestra. Ahora bien, este yo equivale al puro darse cuenta de o al estar despierto para, ya sea de modo explícito o con una conciencia de horizonte, de universo. Pero si el yo es esa conciencia, esa antecedencia respecto a cualquier dato, ni siquiera podemos concebir qué pueda significar ahondar en su conocimiento. Es un punto focal irradiante de objetividad, y conocerlo sólo puede significar ya aguardar pacientemente a que se desarrolle en el tiempo incorporándose los contenidos que van precipitando como experiencias concretas de sí mismo. Como veremos, Husserl retorna en cierto modo a Leibniz. Vichara, en cambio, es una indagación que desiste de la anterioridad de lo dado y reserva el significado último de "yo", más allá de toda auto-identificación, a un Sí mismo (Self o Atman) que trasciende la subjetividad hacia dentro.

16 Vid. Radhakrishnan, S., Indian Philosophy, II, Oxford University Press, Londres, 1999, 4645; 471-2.

17 Cfr. Hua I, 67. 


\section{Reducción Al Ego cogito}

La reducción fenomenológica es una reducción al ego cogito, que es como en la vía cartesiana, en el modo cartesiano de introducirse en la fenomenología, se denomina al yo puro. "Reducción» quiere decir, por un lado, eliminación hasta cierto residuo y, por otro, regreso a lo nuclear u originario, que es precisamente ese residuo. Pero ese residuo, que es el ego cogito, no es una parcela del mundo que haya resistido a la reducción. En este punto es donde Husserl continúa el camino cartesiano allí donde el propio Descartes se extravió. En un primer momento, nos dice Husserl, Descartes obtiene el ego cogito que surge tras la duda universal, pero, inmediatamente, lo convierte en la mens sive animus de la tradición ingenua, en una cosa que piensa ${ }^{18}$, en parte del mundo.

Una vez obtenido el criterio de evidencia como lo dado en sí mismo, Husserl demuestra que existe la posibilidad apodíctica del no ser de la totalidad del mundo que se experimenta, pues en toda experiencia empírica hay algo no dado efectivamente, que es el ser verdadero de lo percibido: la exterioridad (aussereinander) de lo mentado. Juzgar es un «mentar lejano a las cosas ${ }^{19}$. No obstante, esto no afecta al factum que se experimenta de esta o aquella cosa dándose de este modo o de otro. Si a lo conocido lo considero un factum frente al que no tomo posición, aunque ese factum comprenda una toma de posición, en ese caso está dado presencialmente y, por lo tanto, es evidente en sí mismo.

Aquí nos encontramos con la epojé. Gracias a la nueva actitud egológico-reflexiva (que sólo es nueva en tanto que cese de una actitud habitual), todo el mundo de la experiencia ingenua es puesto fuera de juego. La experiencia ingenua es sustituida por la experiencia fenomenológica «que sigue apareciendo tal como aparecía antes, con la única diferencia de que yo, en cuanto el que reflexiona filosóficamente, ya no efectúo, no mantengo en vigor la creencia natural en el ser, propio de la experiencia ${ }^{20}$. Independientemente de si el circundante mundo concreto de la vida (el nuevo reino fenomenológico, reducido) es o no para mí algo existente, en cualquier caso es aquello que hace posible que yo en un futuro pueda decantarme por su existencia o su no existencia y, en general, es lo que hace posible que pueda alcanzar cualquier verdad acerca de él. Es decir, el ser del ego puro y sus cogitaciones precede al ser natural del mundo del que yo en cada caso puedo hablar ${ }^{21}$.

El sentido que pueda tener para el yo natural la experiencia de algo percibido como existente, predetermina como posibilidad tal experiencia. Así, se puede afirmar que tal experiencia está co-constituida trascendentalmente a partir de esa estructura de sentido a priori que, de ningún modo, se encuentra entre el acervo intuitivo de la cosa dada. Y esto es lo que la actitud ingenua no puede entender porque simplemente supone tal transcendencia sin aclarar su sentido. En general, «cualquier ser verdadero es un polo ideal frente a la conciencia efectiva, pero justamente un polo prescrito esencialmente en ella misma ${ }^{22}$ como horizonte de un

18 Cfr. Hua I, 63.

19 Husserl, E., Meditaciones cit., 16 (Hua I, 51).

$20 \quad$ Ibidem, 27 (Hua I, 59).

21 Cfr. Hua I, 61.

22 Husserl, E., Las Conferencias de Londres cit., 82. 
posible enriquecimiento ilimitado de su conocimiento. En este sentido la conciencia es intencional, es conciencia de algo: sintetiza vivencias como concreciones de un esquema o sostén a priori, que es lo propiamente-no-percibido-en-sí-mismo: esa mismidad que la actitud ingenua proyecta ahí afuera. Las daciones concretas son subjetivas en el sentido de privadas, pero no así sus polos ideales.

El ego cogito no es el de este o aquel hombre. El ego cogito no puede añadir nada en el nivel de lo conocido, pues estaría dispuesto en el mismo orden del tiempo objetivo con eso conocido ${ }^{23}$, simplemente le otorga la categoría de cogitatum, de fenómeno puro, eliminando cualquier fuerza dóxica que comprometa al ego dejándola dentro de la propia experiencia como ingrediente suyo, como modo. El yo puro está "preservado de todo comercio inadvertido o clandestino con el objeto» ${ }^{24}$.

Esta es la reducción al ego cogito. La libre epojé revela al yo puro: «ese yo y la vida del yo que me queda (...) no es un trozo de mundo, y decir, "Yo soy, ego cogito" no significa ya: "Yo, ese hombre, soy" ${ }^{25}$. Gracias al método de la epojé «me capto puramente como yo» ${ }^{26}$, me gano a mí mismo como ego puro: "ya no soy yo el que se encuentra como hombre en la experiencia natural de sí mismo» ${ }^{27}$, en su lugar, obtengo "el reino de la experiencia fenomenológica-trascendental de mí mismo» ${ }^{28}$.

\section{LAS OSCILACIONES DEL YO}

El yo reducido o puro es por lo tanto la subjetividad para la cual todo aquello que también podría denominarse ente, es objeto, por lo tanto, es el yo último y absoluto "para el que son todos y cada uno de los objetos intencionales» ${ }^{29}$. En este sentido es solus ipse. El ego cogito o yo puro «está perfectamente vacío de componentes esenciales, no tiene absolutamente ningún contenido desplegable, es en sí y por sí indescriptible: yo puro y nada más ${ }^{30}$. Pero, de la misma forma que hay un polo-cosa trascendente que, no obstante, pertenece por completo al ámbito absoluto de la subjetividad trascendental, pues en tanto que tal polo está prescrito como horizonte (esa unidad percibida, empírica, que, sin embargo, no es dada), también hay un polo-sujeto que no está fuera de este ámbito sino que más bien es el centro irradiante de la objetividad. Mientras que el polo-cosa no es independiente de la conciencia (es siempre para la conciencia), el yo es más bien el único absoluto independiente: quien efectúa todas las donaciones de sentido ${ }^{31}$.

23 Cfr. Hua II, 44.

24 LÉvinas, E., Fuera del sujeto, Caparrós Editores, Madrid, 1997, 167.

25 Husserl, E., Meditaciones cit., 35 (Hua I, 64).

26 Ibidem, 29 (Hua I, 60).

27 Ibidem, 35 (Hua I, 64).

28 Ibidem, 36 (Hua I, 65).

29 Husserl, E., Las Conferencias de Londres cit., 73.

30 Husserl, E., Ideas cit., 190 (Hua III/1, 179).

31 Husserl, E., Las Conferencias de Londres cit., 74. 
Husserl anuncia una crítica de la experiencia trascendental de sí mismo que no llega a realizar ${ }^{32}$, pero sí nos dice que el contenido a priori de tal experiencia, que es realmente lo absolutamente indubitable, no es la mera identidad del "yo soy», sino una estructura universal y apodíctica de dicha experiencia, es decir, que esta experiencia también tiene un polo-horizonte que, como un sujeto vacío de predicados, predelinea cualquier posible experiencia de sí mismo susceptible de perfeccionarse ad infinitum ${ }^{33}$. La experiencia transcendental de sí mismo es un autodescubrimiento que se concreta en una sucesión de dalidades particulares de la experiencia real y posible de sí mismo que tienen de absolutamente evidente sólo esa estructura que las predispone a priori.

Por lo tanto, el ego se constituye a sí mismo continuamente como existente pues no se capta a sí mismo simplemente como vida que fluye sino como el yo que tiene esas vivencias que fluyen y, de este modo, se da una segunda clase de polaridad que abraza la multiplicidad de cogitaciones como cogitaciones del polo-sujeto que vive en todas las vivencias de la conciencia. Por este motivo, el ego existe para sí con continua evidencia, y con cada nuevo sentido objetivo que irradia de este centro, él gana una propiedad nueva y permanente ${ }^{34}$. Las experiencias que tiene de sí mismo lo explicitan a lo largo del tiempo, o sea, lo enriquecen objetivamente. La semejanza entre esta concepción y la monadología de Leibniz es señalada repetidas veces por Husserl ${ }^{35}$.

Estas propiedades permanentes vienen a ser experiencias de sí mismo que, al sedimentar, se convierten en hábitos co-conscientes y por lo tanto co-constitutivos del yo concreto ${ }^{36}$. Sin embargo, el yo puro es anterior a cualquier experiencia de sí mismo que lo enriquezca. No puede tener habitualidades (Habitualitäten) que lo refieran a la corriente de vivencias, así que no es algo que pueda describir fenómenos puros ni, en general, emprender ninguna tarea. Obviamente, para hacer fenomenología tiene que devenir el yo que toma posición, el yo que toma iniciativas. Es decir, que, bajo nuestro punto de vista, el yo que hace descripciones fenomenológicas es el yo humano del filósofo principiante que practicó la reducción, pero que ahora comprende su anterior actitud ingenua. Es el ego que recupera la experiencia del mundo desde la experiencia trascendental: se sabe yo puro pero, también, revestido de individualidad empírica, intersubjetiva e histórica, y en cuanto tal interviene, como el actor de un drama, en el mundo y en la sociedad. El mundo es ahora parte de la propia vida de la subjetividad trascendental, un mundo íntimo en el que se encuentra ese yo individual con los demás gracias a la corporeidad. Se trata, en efecto, de una vida nueva y de un ser humano transformado.

32 Cfr. Hua I, 67 y ss. Este lapsus vendría a ser subsanado por Eugen Fink con su VI Meditación (Cfr. SAN MARTín, J., o. c. 199-200).

33 Cfr. Hua I, 67.

34 Cfr. Hua I, 100.

35 Vid. Iribarne, J. V., La fenomenología como monadología, Academia Nacional de Ciencias/Centro de Estudios Filosóficos, Buenos Aires, 2002.

36 Para entender el concepto de pasividad en la fenomenología genética nos ha resultado especialmente útil el artículo de Osswald, A. M., «El concepto de pasividad en Edmund Husserl» en Areté. Revista de Filosofía (26/1, 2014) 33-51. 
Pero si, como vemos, «el yo trascendental es el mismo que, en la mundanidad, es el yo humano» ${ }^{37}$, ¿por qué ese yo humano se experimenta así, como yo mundano? La pregunta es por la constitución genética del yo empírico e intersubjetivo del ego desarrollado ${ }^{38}$ (entwickelten). La respuesta, en esencia, es que la conciencia fáctica, desde el punto de vista transcendental, aparece como un determinado curso de la conciencia, es decir, como añadiendo todas esas habitualidades a la pura conciencia de las que se había desprendido, precisamente, en la reducción.

Cito textualmente a Husserl en este punto tan importante: «Es claro que puede decirse que yo, en cuanto yo de la actitud natural, soy también y en todo momento yo trascendental, pero que sé acerca de ello tan solo al llevar a cabo la reducción fenomenológica» ${ }^{39}$. Ingarden, a propósito de este fragmento, opina que ese «también» debería ser eliminado porque ambos "yo» son incompatibles. Sólo se puede decir que el yo puro, antes de la reducción, no se da cuenta de su pureza, o sea, de sí $\mathrm{mismo}^{40}$. Pero según nuestro punto de vista esto no es del todo acertado. Yo transcendental y yo natural no tienen características contrapuestas porque sólo uno de ellos tiene características mientras el otro es puro. Por otra parte, el yo puro no puede darse cuenta de nada nuevo tras la reducción, porque no se sitúa en el tiempo. Ese «también» indica precisamente que el yo natural añade algo al yo trascendental o puro. Gracias a la reducción, el yo natural se descubre a sí mismo como yo puro tras dejar en suspenso eso que añadía: su desarrollo o despliegue y, en definitiva, su carácter co-consciente. Esto supone un cese de la actitud ingenua del yo natural y su transformación en la actitud fenomenologizante del actor que desarrolla su papel en un drama en cuyos entresijos se quedan todas y cada una de sus tomas de posición, como en un juego. Lo importante no es tanto qué hace o qué dice el actor sino cómo lo hace o cómo lo dice.

El yo natural se co-constituye genéticamente como ese yo personal estable y permanente añadiéndose determinaciones habituales, como hemos visto. Por lo tanto, la reducción fenomenológica trascendental debe ser considerada como un desandar dicha génesis: un despojarse de todas esas sedimentaciones que lo individualizan como algo empírico e intersubjetivo, con un aquí y un ahora, con un pasado y un futuro, y con nombre y apellido.

Todo «lo que en la vida se nos presenta como ya concluido, por así decirlo, como mera cosa existente ${ }^{41}$ es fruto de una síntesis pasiva que suministra constantemente el material, la cosa pre-dada, a las actividades humanas. Ahora bien, el sujeto que constituye el mundo precisa estar corporalmente encarnado en el mundo que constituye $^{42}$. Sin el «aquí absoluto, desatendido pero siempre co-consciente (en el

37 Husserl, E., citado en SzILASI, W., o. c. 113.

38 Cfr. Hua I, 113.

39 Husserl, E., Meditaciones cit. 52 (Hua I, 75).

40 Cfr. Hua I, 212-4. Las observaciones críticas de Ingarden al texto francés de las Meditaciones, que el propio Husserl solicitó, fueron incluidas como apéndice en el primer volumen de la Husserliana.

41 Husserl, E., Meditaciones cit., 104 (Hua I, 112).

42 Cfr. Hua XXXVI.Transzendentaler Idealismus. Texte aus dem Nachlass (1926-1935), Kluwer Academic Publishers, Dordrecht, 2003, 135. 
propio cuerpo orgánico siempre co-apareciente») $)^{43}$, sin el hic et nunc de un cuerpo propio sentido y sentiente, no parece posible ninguna síntesis pasiva. La conciencia intencional es pues conciencia encarnada.

Esta constitución genética no es productiva, porque constituye modos de experiencia, y no es un mero uno-tras-otro, sino uno-a-partir-de-otro ${ }^{44}$ : es, utilizando una imagen que pensamos que puede ayudar a entenderla, en cascada por sedimentación. Gracias a la sedimentación de las experiencias que se convierten en hábitos, la experiencia co-constituida es, a la vez, co-constituyente del siguiente nivel. Hay un elemento pasivo que es co-constituyente en la génesis del siguiente nivel en la medida en que es un factor co-consciente. La conciencia se origina de la conciencia en cuanto conserva los cumplimientos constituidos en el proceso del devenir ${ }^{45}$.

La libre epojé deconstruye esa exterioridad del mundo pero, con ella, también al propio yo empírico en tanto que experimentado en ella ${ }^{46}$. En siguientes niveles, gracias a la corporeidad, se constituye la experiencia del extraño, del alter ego, y de la intersubjetivad que, a su vez, es co-constituyente del mundo intersubjetivo con sus infinitos contenidos. Por otra parte, los nuevos niveles revierten en los anteriores (por ejemplo, la experiencia de las relaciones cuerpo-mundo está culturalmente condicionada, por no hablar de la experiencia del alter ego).

La reducción al yo puro es la eliminación de todo factor objetivo pre-dado en una experiencia que, como sedimento, se convierte en hábito co-consciente del yo concreto, personal y permanente que empezó a filosofar: su reducción a conciencia pura. Según Lévinas, «el yo puro, sujeto de la conciencia transcendental en la que se constituye el mundo, está él mismo fuera del sujeto: sí mismo sin reflexión, unicidad que se identifica como despertar incesante» ${ }^{47}$.

\section{ATMA VICHARA: LA INDAGACIÓN DEL Sí MISMO}

Desde el punto de vista del fenomenólogo que ha practicado la reducción, ¿qué sentido puede tener un yo falso? Obviamente no puede significar un yo que no forma parte de la realidad. Más bien lo contrario. Como hemos visto, la reducción depura al yo de todo comercio inadvertido con el objeto, así que un yo falso sería un yo que comerciara inadvertidamente con el objeto: un objeto que apareciera como yo, porque el yo está del lado de la noesis, no del noema. Ahora bien, esto es lo que ocurre cada vez que pienso «yo». Aunque diga «el yo es impensable», lo estoy

43 Husserl, E., Meditaciones cit., 55 (Hua I, 78).

44 Cfr, Hua XI, 338.

45 Cfr. Steinвock, A. J., «Husserl's static and genetic phenomenology: Translator's introduction to two essays. Essay 1: Static and genetic phenomenological method. Essay 2: The phenomenology of monadic individuality and the phenomenology of the general possibilities and compossibilities of lived-experiences: static and genetic phenomenology» en: Continental Philosophy Review $(31 / 2,1998) 149$.

46 La experiencia de sí mismo como carne (chair), como ser carnal, será tematizada por Merleau Ponty como quiasmo cuerpo-mundo, como punto en que se cruzan el tocar y lo tangible. Cfr. Merleau Ponty, M., Lo visible y lo invisible, Seix Barral, Barcelona, 1970, 166.

47 Lévinas, E., $O, C, 168$. 
pensando y, por lo tanto, haciendo que pase inadvertidamente la aduana. Con ello obtengo un yo pensado, objetivo. Y justamente ese yo objetivo es el sujeto "yo».

Así es justamente como lo entiende la tradición advaita. Si me pregunto ¿quién soy?, se hace evidente que no puedo ser nada de todo cuanto pueda pensar, creer, o imaginar. El yo falso que debo desechar por lo tanto es el yo pensado, el pensamiento "yo»; ahora bien, ese es el sujeto "yo»: un estar presente para sí. A ese yo falso es al que en la actualidad llamamos «ego» en sentido narcisista: el ego es, a la vez, la ilusión y el que cae en ella ${ }^{48}$ porque no es más que una presunción.

Husserl tampoco comete ese error. Si hay un pensador al que nada se le escapa o le pasa inadvertido es a él. El yo no puede ser algo dado. Lo dado es constituido sintéticamente, mientras el yo es la conciencia constituyente, por lo que su conocimiento debe ser concomitante, es decir, mientras conoce. Y así, mientras conoce, se conoce como polo subjetivo a priori respecto a cualquier experiencia. Pero esta conciencia como el darse cuenta de algo quiere decir para el advaita, como veremos, conciencia en estado de vigilia: estar despierto para algo.

Los doctores clásicos de esta escuela (a parte de los legendarios rishis) son Gaudapada y, sobre todo, Shankara, ambos probablemente de los siglos VII-VIII d. C., pero las enseñanzas del advaita no sufren cambios en lo sustancial con el tiempo, y dos maestros del siglo XX, como Sri Ramana Maharshi y Sri Nisargadatta Maharaj, las han transmitido con la ventaja de que la cercanía histórica, así como el carácter dialogado de sus enseñanzas, facilita su comprensión en la actualidad ${ }^{49}$. No obstante, la doctrina advaita es meramente purgativa: no dice lo verdadero, porque esto es imposible, sino que sólo elimina errores presentando lo falso como falso.

«Vichara» es un término sánscrito transcrito que significa indagación o investigación, y que es empleado en la tradición advaita para significar la indagación que debe emprenderse antes que cualquier otra: la indagación de sí mismo. Al que busca conocer las cuestiones últimas acerca del alma, del mundo o de Dios, se le aconseja que se haga la pregunta "¿quién soy?» ${ }^{50}$. Se le insta a que aclare en primer lugar esta cuestión antes de proseguir con otras, pues todas las demás cuestiones dependen de ésta.

Pero cualquier respuesta que se diera a esa pregunta del tipo «soy esto o aquello» no podría ser correcta por algo que ya hemos visto: el yo nunca está dado. A eso que realmente soy pero que no puede serme dado se le denomina «Atman» o «Sí mismo» (Self) en esta tradición. Como no puede darse un conocimiento

48 Cfr. Un Monje de Occidente, Doctrina de la no-dualidad y cristianismo, José J. DE OLAÑETA, Palma de Mallorca, 2008, 105.

49 Para las citas textuales de estos dos maestros utilizaremos las siguientes traducciones al castellano: Conversaciones con Sri Ramana Maharshi, tomos I y II, Sanz y Torres, Madrid, 2006 (en adelante Conversaciones) y Yo soy Eso. Conversaciones con Sri Nisargaddatta Maharaj, $2^{\mathrm{a}}$ ed., Editorial Sirio, Málaga, 2003 (en adelante Y.S.E.). Señalaremos las páginas de estas dos obras así como la página de la edición en lengua original del libro de Maharshi, Talks with Sri Ramana Maharshi, Sri Ramanashramam, Tiruvannamalai, 2006 (en adelante Talks) y la sección correspondiente a la edición inglesa del libro de Nisargaddatta, I am That (translated by Maurice Frydman), Sudhakar S. Dikshit, Bombay, 1973 (en adelante I.A.T.).

50 Cfr. I.A.T., §21. 
reflexivo del verdadero yo, esta indagación procede, como recordemos que hace la husserliana, por reducción, eliminando el no-Si mismo: "(Aham, aham), "yo-yo" es el Sí mismo; (Aham idam) "yo soy esto" o "yo soy eso", es el ego. Cuando el "yo" es mantenido sólo como "yo", es el Sí mismo; cuando sale por la tangente y dice “esto", entonces es el ego» ${ }^{51}$. El ego es, pues, el yo en estado de identificación: un salirse por la tangente que es síntoma de falta de indagación, de debilidad mental o letargo ${ }^{52}$.

El correlato exacto de la reducción al yo puro en el advaita es drisya vilaya: la desaparición del mundo objetivo. La conciencia se aliena como el sujeto (drik) y el objeto (drisya). Puesto que el yo está del lado del sujeto, del veedor, el método consiste en una depuración objetiva que hace al sujeto cada vez más sutil hasta que sólo sobrevive como sujeto absoluto sin mezcla objetiva alguna ${ }^{53}$. Pero, como el sujeto es la proyección del yo, el reflejo del yo, en el pensamiento, hay que ir contracorriente, hasta la fuente de esa proyección, para encontrar el verdadero significado de "yo ${ }^{54}$. De modo que la desaparición del mundo objetivo sólo se completa cuando desaparece, con él, el sujeto ${ }^{55}$. La indagación de “¿Quién soy yo?” significa encontrar la fuente del "yo" "56: el yo-fuente.

Como dice Nisargaddatta, «el camino de regreso a uno mismo pasa por el rechazo y el abandono ${ }^{57}$. Ese enriquecimiento conservado por el yo que se desarrolla a sí mismo, del que nos habla Husserl, debe ser abandonado. La reducción de vichara consiste precisamente en la renuncia (sanyasa) de todos esos sedimentos reflexivos que desarrollan e individualizan al yo, pues son esos lodos los que lo ocultan. En el camino de salida o hacia afuera (pravritti) se adquieren unas propiedades que deben ser abandonadas en el camino de regreso (nivritti) ${ }^{58}$, puesto que sólo en la anulación y autonegación total es posible conocer nuestra verdadera naturaleza ${ }^{59}$. La pregunta que plantea vichara apunta al ser verdadero, a la naturaleza real (svarupa) de uno mismo, pero la puerta hacia el ser verdadero de uno mismo sólo se abre hacia adentro, por lo que uno debe apartarse para no obturarla.

Husserl no penetra en ese vacío al que conduce en última instancia su reducción transcendental y que se revela al esfumarse el sujeto mismo. Y, sin embargo, en ese no ser nada puede vislumbrarse la generosidad más elevada ${ }^{60}$ en la que profundizará Heidegger con una noción de pobreza (la pobreza del Pastor del Ser) y de anonadamiento (Nichtung) que recordará al Meister Eckhart.

Cada uno, al emprender vichara, debe indagar sobre ese uno mismo que pretende indagar. Entonces, al dar ese paso atrás para buscarse, reconoce que no es quien pretendía ser precisamente porque ahora lo abarca como objeto. Pero como

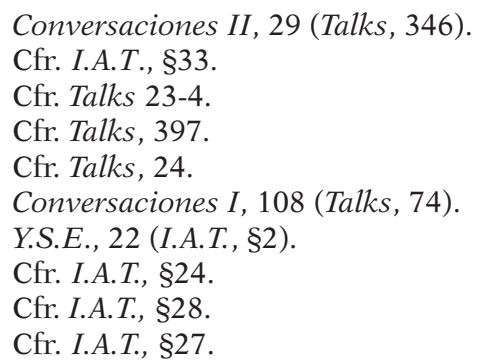


lo pretendía, tal revelación hace que se esfume como una impostura desenmascarada: "Para quienquiera que investigue el origen del pensamiento "yo", el ego perece. Esta es la verdadera investigación. Entonces se encuentra al verdadero yo brillando por sí mismo» ${ }^{61}$. En vichara, como ocurre en la fenomenología de Husserl, la reducción no sólo pone en fuera de juego al mundo sino también al sujeto, es decir, al yo que indaga ${ }^{62}$, al yo del filósofo principiante: "El método se resume en "sé en quietud”. ¿Qué significa "sé en quietud”? Significa: “destrúyase a usted mismo”63, "sea libre de pensamientos" 64 . Al quedar fuera de juego el ego, el sujeto "yo", se suspende la función pensante.

Atma vichara, el conocimiento del atman o del Sí mismo, es un conocimiento que no puede ser adquirido: «en lugar de buscar lo que no tiene, encuentre aquello que nunca perdió» ${ }^{65}$. Una de las imágenes que suele utilizar Maharshi es la de la mujer que creyó perdido su collar, lo buscó desesperadamente y lloró su pérdida, hasta que una amiga le indicó que lo tenía abrochado alrededor de su cuello ${ }^{66}$. El collar siempre estuvo allí y, sin embargo, la alegría al descubrir que no lo había perdido era la misma que hubiera tenido la señora en el caso de haberlo recuperado realmente. Es decir, hay un amanecer de la sabiduría que consiste en el final de una ignorancia: «la realización (...) es sólo la eliminación de todo camuflaje» ${ }^{67}$.

\section{AVIDJA: LA IGNORANCIA COMO CONDICIÓN DE POSIBILIDAD DEL CONOCIMIENTO MUNDANO}

Para el advaita, la realidad subyace a la irrealidad ${ }^{68}$, en el sentido de que la irrealidad sólo se da como ocultamiento de la realidad. ¿Cómo se oculta algo sin utilizar otra cosa para cubrirlo? Obviamente hay que conseguir que su visión parezca la de otra cosa, es decir, hay que camuflarla o disimularla. Si tenemos éxito y el observador la toma por otra cosa, en realidad la ha visto, pero lo ignora. Su ignorancia no lo es de lo que hemos camuflado, porque lo ha visto. En el sentido de desconocimiento de lo real, la ignorancia es imposible. Acudiendo al ejemplo favorito de la tradición advaita, el de la soga en el suelo que es confundida con una serpiente, es claro que cuando uno se percata de que la serpiente que creía ver en el suelo de la habitación en penumbras ocultaba realmente una soga, la serpiente se esfuma sin más: uno siempre estuvo viendo la cuerda, lo real.

61 Conversaciones I, 258 (Talks, 191).

62 S. Radhakrishnan critica la posición mantenida por Gaudapada en sus Karika en relación a la irrealidad de todos los objetos tratados, incluido el sujeto que los trata, y elogia a Shankara por haber mantenido una posición más equilibrada al respecto. Por nuestra parte no encontramos discrepancia alguna entre ambos maestros en este punto. Vid. RADHAKRISHNAN, S., o. c. 463-5.

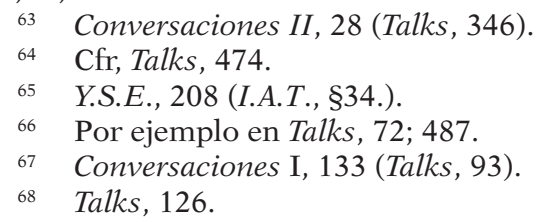


Avidja, la ignorancia, no es ausencia de visión, sino poder de ilusión (mayal shakti $)^{69}$ que, en cierto modo, radica en lo real, pues es la manifestación de lo real que, aislada de su fuente como presencia, como lo dado, lo encubre. La ignorancia que, gracias a vichara, debe dejar de ser ignorada, ponía aquello por lo que era tomado el Sí mismo, esto es, el sujeto individual que emprendió la tarea de autoindagarse:

«Indagación significa que el indagador se considera a sí mismo separado de la indagación. Mientras dure esta dualidad debe proseguirse la indagación; es decir, hasta que desaparezca la individualidad (...) El objeto de la indagación es encontrar la verdadera naturaleza del Sí mismo como Conciencia. Practiquemos la indagación mientras persista la separatividad.» ${ }^{70}$

En la absoluta tiniebla (absoluta nesciencia) no hay confusión. Para que la haya se precisa una luz que, como la luz reflejada de la luna, alumbre en la oscuridad: «al interponerse la oscuridad o la ignorancia, el Conocimiento Puro (chit) parece diferente de lo que Él es realmente; entonces es visto como "yo" y el "mundo" »71. El conocimiento puro es sin conocedor ni conocido, los cuales aparecen y desaparecen simultáneamente ${ }^{72}$. El conocimiento propio del ego es conocimiento-en-laignorancia: «cuando nosotros vemos nuestro Sí mismo, no hay ningún mundo; y cuando perdemos la visión del Sí mismo, nos encerramos a nosotros mismos en el mundo» ${ }^{73}$. La apertura intencional de la conciencia que, como hemos visto al exponer el pensamiento de Husserl, tiene que ver con su asociación al cuerpo, es su extroversión ${ }^{74}$ : sólo se lleva a cabo pagando un precio que es el olvido del Sí mismo. Cuando aparecen el yo y el mundo como separados se ha producido una distracción, una desatención, una especie de letargo. El Sí mismo es autoefulgente, y ello quiere decir que no puede darse como objeto de conciencia, pero está oculto en todos los actos de conciencia ${ }^{75}$. Todo objeto es un ocultamiento inadvertido de esa autoefulgencia del Sí mismo.

En definitiva, la ignorancia es el olvido del Sí mismo que genera la exterioridad, el ser de la superficie del que habla Husserl en el que yo y mundo se oponen como realidades separadas.

\section{Ahamkara: El PENSAMiento «YO»}

La conciencia pura es siempre virgen y fresca, no retiene nada: es un continuo morir al ahora ${ }^{76}$. Si se desarrolla conservando sus cumplimientos, como dice Husserl, es sólo como conciencia refleja (abhasa), que es el ámbito de la subjetividad: un presente continuo que retiene el pasado como profundidad del ahora.

69 Cfr. Zimmer, H., Philosophies of India, Princeton University Press, Princeton, New Jersey, 1989, 415-6.

70 Conversaciones II, 155 (Talks, 447).

71 Ibidem, 300 (Talks, 560-1).

72 Cfr. I.A.T., §5.

73 Ibidem, 269 (Talks, 536); Cfr. I.A.T., §25.

74 Cfr. Talks, 379.

75 Cfr. Dasgupta, S., A History of Indian Philosophy, Motidal Banarsidass, Dheli, 1975, 278.

76 Cfr. I.A.T., §33. 
El ego, como ya hemos indicado, aparece como reflexión. La idea de reflejo supone cierta dualidad: el rayo de luz y la superficie incidente desde la que se proyecta como luz reflejada tras sufrir un cambio de dirección. El punto de incidencia redirige la luz, convirtiéndose en foco secundario de luz: administra la luz en una determinada dirección, pero no es su fuente real. No es luminoso de suyo.

Esa posición que se convierte en falsa fuente de luz equivale a una identificación limitadora con lo iluminado, con lo pensado, que extrapola la fuente de luz al foco subjetivo: «La conciencia es ilimitada. Al devenir limitada, simplemente arroga sobre sí misma esa posición [la de ser el presenciador]. Realmente no hay nada que presenciar. Ella está simplemente SIENDO ${ }^{77}$.

Cuando me miro en un espejo, la imagen virtual parece mirarme, sin embargo, sólo soy yo, el que está a este lado del espejo, el que mira realmente. La existencia no pasa al otro lado del espejo. De parecido modo, el ego se convierte, por mor de la falsa identificación que extrapola la conciencia al otro lado del espejo, en elemento co-consciente a partir de ese nivel. La conciencia extrovertida es, paradójicamente, la conciencia refleja: «El conocimiento de ser el presenciador es sólo la función de abhasa (la conciencia refleja)» ${ }^{78}$.

En la tradición advaita, a los pensamientos con los que identificamos a las cosas se les llama "superposiciones» o "adiciones» (upadhis) que podemos también traducir por «atributos». Toda diversidad es fruto de esa identificación-superposición (adhyasa). La identificación falsa en el caso del pensamiento "yo» equivale a una auto-limitación y a una auto-segregación: "Solo Bhuma (la Perfección) es. Es infinita. De ella surge esta conciencia finita que toma un aditamento limitativo (upadhi). Esto es abhasa o reflejo ${ }^{79}$. El sujeto es el aditamento limitativo (recordemos que en realidad se trata de un objeto) que convierte a la conciencia en conciencia refleja (conciencia de algo y de alguien), en subjetividad privada.

El ego surge simultáneamente a su identificación con un objeto. Sin esa asociación, no se sostiene. Es como la oruga que sólo suelta su soporte después de agarrar otro ${ }^{80}$. La identificación-limitación de la que surge el ego natural-empírico es la identificación con el cuerpo: la conciencia «soy el cuerpo» (dehatma buddhi). Es natural porque surge cada vez que despertamos a la vigilia. Nisargaddatta Maharaj la precisa más como la conciencia «soy el cuerpo en el mundo» ${ }^{81}$. Emerger del sueño profundo es, en cierto modo, un encarnarse en el mundo. Sin la sensibilidad orgánica no sería posible el estado de vigilia: el estar despierto de un sujeto ${ }^{82}$ (como hemos visto, según Husserl, sin el hic et nunc del cuerpo no hay posibilidad de síntesis).

Como decimos, el ego necesita soportes. Así que lo propio de él es definirse, identificarse con esto y aquello, con lo cual, la conciencia adquiere nuevas envolturas (kosa) que podemos llamar «complejos», definiciones de uno mismo que

77 Conversaciones I, 210 (Talks, 155).

Ibidem, 112 (Talks, 76-7).

Ibidem, 110 (Talks, 75).

Cfr. Talks, 256.

Y.S.E., 17 (I.A.T, §1).

82 Cfr. Polo, L., «La fenomenología del despertar» en: Anuario Filosófico (27/2, 1994) $681-2$. 
adquieren carácter co-consciente y que se relacionan con el agregado de tendencias latentes, de predisposiciones o vasanas ${ }^{83}$. A la envoltura corpórea (que es la primera puesto que la idea "yo» sólo surge a un ego incorporado ${ }^{84}$ : el cuerpo es un adjunto necesario del ego $^{85}$ ) le siguen otras.

La identificación puede llegar muy lejos. Ramana Maharshi se muestra crítico con la práctica de "Aham Brahmasmi», esto es, con la de meditar o repetir "Yo soy Brahman» («yo soy Dios»), porque si uno es Dios no anda todo el rato recordándoselo, y si no lo es, no tiene derecho a decirlo. "Yo soy Brahman» es, simplemente, identificarse con una idea: "Yo soy" es Dios — no pensar “yo soy Dios”—»" Vichara no se detiene en ninguna identificación, sea cual sea.

El sujeto está animado desde dentro por la conciencia, pero en sí mismo es como una de esas figuras de atlas que parecen soportar sobre sus hombros la carga de un edificio, cuando en realidad no aportan otra cosa que un gesto que lleva al error. Vichara es lo que lleva a la conciencia más allá del sujeto. En este estado, la luz reflejada se oscurece ante el brillo del Sí mismo y vichara da paso al silencio: el sentido de ser el indagador ha cesado y sólo permanece el silencio (mouna): «El silencio es “yo" ${ }^{87}$.

\section{El CENTRO-CORAZÓN (HRIDAYA)}

La superposición limitadora «soy el cuerpo en el mundo» segrega a la conciencia de la vigilia de aquella que la abarca y de donde surge: «¿Qué es la conciencia del cuerpo? Analícela. Debe haber un cuerpo y una conciencia limitada a él (...) ésta debe estar en otra conciencia que es absoluta e inafectada. Permanezca en ella» ${ }^{88}$.

Esta conciencia de ser el cuerpo en el mundo se aísla de su fuente, del punto central en el que surge, que es el corazón: «busque su fuente (de usted). La indagación le lleva al corazón automáticamente» ${ }^{89}$. El yo «impregna la totalidad de nuestro cuerpo hasta la punta de los dedos» como afirma el Brihadaranyaka Upanishad ${ }^{90}$, pero cada uno se señala el centro del pecho cuando quiere decir «yo» con un gesto. Aunque nuestra conciencia penetra todo el cuerpo, surge desde un centro y se sumerge en ese mismo centro ${ }^{91}$. Señalar al Sí mismo conduce adentro de uno mismo.

La conciencia limitada al cuerpo se aísla de su fuente como función pensante (manas), que es la mente agitada. Toda agitación es separación de la fuente ${ }^{92}$. La función pensante es la mente debilitada y dominada por el ego como por un encantamiento: «El pensamiento "yo no he visto", la expectativa de ver y el deseo

Cfr. Talks, 298.

Cfr. Talks, 25.

Cfr. Talks, 379.

Conversaciones II, 15 (Talks, 335).

Conversaciones I, 284 (Talks, 212).

Conversaciones II, 92 (Talks, 397).

Conversaciones II, 63 (Talks, 375).

Cit. en Loy, D., No-dualidad. $2^{\mathrm{a}}$ ed., Kairós, Barcelona, 2010, 39.

Cfr. Talks, 393.

Cfr. Talks, 379. 
de obtener algo, son todas operaciones del ego ${ }^{93}$. Todos los pensamientos están ensartados en un hilo que es el pensamiento "yo»" ${ }^{94}$. El ego penetra todos los pensamientos: "Los pensamientos surgen debido a que hay un pensador. El pensador es el ego (...) El ego es el pensamiento-raíz del que surgen todos los demás pensamientos ${ }^{95}$. Pero el ego y sus pensamientos son como sombras que parecen agitar la superficie de un agua en calma, que es la conciencia pura.

La mente por sí misma es inoperativa ${ }^{96}$ : "[el deseo] es lo que da nombre y forma ${ }^{97}$. La actividad del ego esconde "un querer aferrarse y asegurarse a sí mismo, aferrando objetivamente lo otro ${ }^{98}$. Sujeto y objeto son dos vertientes que se apoyan mutuamente. La agitación, la falsa actividad mental, es como la de un órgano burocrático que tratara de evitar su disolución tramitando un expediente interminable. Pero nuestro ser verdadero está sólo supuestamente implicado en ese proceso kafkiano ${ }^{99}$. Tanto el yo pensado (como sujeto) como todas las acciones que le adscribimos, son irreales.

La conciencia pura (chit) equivale a la mente en quietud que es como un espejo frente a otro espejo limpio, es decir, ningún reflejo ${ }^{100}$. Sin embargo, esta quietud es sólo aparente (es quietud de reflejos): la conciencia pura, la mente puramente sattvica es "sirviente del ser»"101 (adviértase la sorprendente coincidencia en este punto con Heidegger y su Lichtung). La conciencia pura es pura transparencia, y cualquier visibilidad en la conciencia equivale a la de una mancha superpuesta ${ }^{102}$. Los objetos encubren la transparencia de la conciencia pura como una sobreimposición que, en realidad, no le afecta, puesto que es esta transparencia de la consciencia la que permite el darse del objeto, precisamente, como su ocultamiento.

A la conciencia pura (chit) se la sitúa simbólicamente en el sahasrara, el loto de los mil pétalos, en la coronilla, porque obviamente representa el apex mentis. No es consciente de ningún otro, sino un despertar anterior a devenir consciente del mundo ${ }^{103}$, que equivale al sueño profundo en estado de vigilia (jagrat sushupti), o a transcender la conciencia «soy el cuerpo». Cuando la propia mente descubre el carácter ilusorio de todas sus representaciones se convierte en mruta manas y antarmukhi manas: la mente muerta y vuelta hacia dentro, hacia el corazón ${ }^{104}$, dentro del cual Eso brilla como "Yo» (ahamiti sphurati). A Eso que brilla dentro del corazón le llama la tradición hindú con distintos nombres (purusa, atman, hiranyagarbha), pero todos son nombres divinos del Sí mismo. El corazón es su sede, allí donde mora

93 Conversaciones I, 212 (Talks, 156).

94 Cfr. Talks, 359.

95 Conversaciones I, 224-5 (Talks, 165).

96 Cfr. Talks, 77.

97 Y.S.E., 30 (I.A.T., §4).

98 Cavallé, M., La sabiduría de la no-dualidad. Una reflexión comparada entre Nisargaddatta y Heidegger, Kairós, Barcelona, 2008, 391.

99 Cfr. Coomaraswamy, A. K., El vedanta y la tradición occidental, Siruela, Madrid, 2001, 100.

100 Cfr. Talks, 480.

101 Y.S.E, 187 (I.A.T., §31).

102 Cfr. I.A.T., §31.

103 Cfr. Talks, 167, 283.

104 Cfr. Talks, 96. 
y resplandece como «Yo» en todos: «cada uno, aunque se le llame "usted”, se llama a sí mismo "yo" (...) No hay ningún“usted” en absoluto. Todos están comprendidos en "yo" » ${ }^{105}$.

Según Maharshi, en los Vedas se usa el corazón para significar el lugar donde brota la noción "yo» ${ }^{106}$. Cada uno indica su sí mismo apuntando a un punto coincidente, puesto que cuando cada uno quiere señalarse a sí mismo, señala su corazón, pero el corazón no sólo es el centro de cada uno, sino que, a su vez, se abre por dentro: es una cavidad, de modo que, para cada uno, señalar su sí mismo equivale a ir hacia adentro. La búsqueda del yo es un trascender en la línea de la intimidad en cuyo fondo sin fondo resplandece el Sí mismo. Por otra parte, para el que se sumerge en el corazón, éste deja de ser un centro, porque ya no hay nada salvo él ${ }^{107}$. Sumergirse en el corazón es adoración: «Todo el tiempo estuve buscando-Te. Pero al realizar mi Sí mismo encuentro que Tú eres el Sí mismo» ${ }^{108}$, dice Maharshi citando a Nammalvar, uno de los doce santos poetas vaishnavitas del sur de la India llamados «alwars» («inmersos»). Todo esto nos recuerda el libro X de Las Confesiones de San Agustín: "Y he aquí que Tú estabas dentro y yo fuera, y ahí te buscaba».

\section{Conclusiones}

En este recorrido hemos comprobados algunas resonancias significativas entre la reducción trascendental y vichara. Ambos métodos parten de una situación que puede ser caracterizada como de olvido de sí, y proceden por depuración objetiva, puesto que el olvido de sí nos exilia al mundo objetivo. Vichara es una trampa ideada para cazar al sujeto mismo que indaga en tanto que objeto co-consciente, en tanto que yo pensado. El ego es una proyección a través de la cual, recorriéndola a contracorriente, descubrimos el verdadero significado de «yo». Pero la reducción transcendental es igualmente implacable y responde a un poderoso aliento espiritual y, en definitiva, a la necesidad de renovar el humanismo. El yo puro es absoluto y último, pero, obviamente, está in interiore homine, compenetrando todas sus vivencias humanas y dotándolas de un sentido supramundano. Pero no debemos situarlo en un a priori respecto a todo objeto como el darse cuenta de, porque ello impide profundizar en él. La vigilia de la razón es más bien la vigilia del cuerpo que la del espíritu (sin el absoluto hic et nunc del cuerpo no se podría sintetizar lo dado según Husserl, mientras que, para el advaita, el estado de vigilia surge con la conciencia "soy este cuerpo en el mundo»). Más allá del darse cuenta se encuentra la conciencia pura (chit), el apex mentis del advaita, el despertar incesante que no termina en un estar despierto para algo, sino que se mantiene siempre nuevo y fresco más allá de todo lo dado y de todo darse cuenta.

Es también significativa la similitud por lo que respecta a la explicación genética en cascada de los distintos niveles y modos de experiencia: si la conciencia se

\footnotetext{
105 Conversaciones II, 46 (Talks, 360).

106 Cfr. Talks, 34.

107 Cfr. Talks, 239.

108 Conversaciones I, 401 (Talks, 295).
} 
convierte en curso individual, subjetivo, de conciencia, si se deja arrastrar en la corriente de vivencias, ello se debe en definitiva a la participación de sedimentos que se adhieren a la conciencia como complejos co-conscientes, como sus vestiduras habituales.

Esta insistencia en mantenerse dentro de esa espiritualidad viviente del mundo que es la conciencia trascendental sin emerger a la superficie, a la exterioridad de las cosas, es común a ambas propuestas. Pero, mientras que la experiencia trascendental de sí mismo parece conducir a Husserl a una monadología, en vichara, la conciencia ahonda en la línea de lo trans-subjetivo renunciando a todo camuflaje, desbrozando toda falsa identificación que oculte al verdadero yo: «Él devino nombrado "yo" »109. Para el advaita, "Yo» es el nombre, la palabra omnipenetrante:

«La naturaleza omnipenetrante del Nombre sólo podrá ser conocida cuando uno reconozca a su propio "yo". Cuando la propia naturaleza de uno no es reconocida, es imposible obtener el Nombre omnipenetrante. Cuando uno se conoce a sí mismo, entonces encuentra al Nombre por todas partes» ${ }^{110}$.

La conciencia pura, la existencia humana, es la apertura incesante, insistente, en el fondo de la cual brilla «la Realidad Suprema, que está en usted y vierte su poder, su luz y su amor en cada experiencia» ${ }^{111}$.

Universidad Internacional de la Rioja

Javier Pérez Guerrero javier.perez@unir.net

[Artículo aprobado para publicación en enero de 2018]

109 Conversaciones II, 246 (Talks, 517). Se trata de una cita del Brihadaranyaka Upanishad.

110 San Namdev, cit. en Conversaciones II, 130 (Talks, 428).

111 Y.S.E., 31 (I.A.T., §4). 